\title{
Medico-legal and bioethical perspectives following the constitutional legitimacy of assisted suicide in Italy
}

Medico-Legal Journal $0(0)$ I-4

(C) The Author(s) 2020 Article reuse guidelines: sagepub.com/journals-permissions DOI: $10.1177 / 0025817220923687$ journals.sagepub.com/home/mlj @SAGE

\author{
Andrea Cioffi', Giuseppe Bersani ${ }^{2}$ and Raffaella Rinaldi'
}

\begin{abstract}
Assisted suicide is the subject of much debate throughout the world. In Italy, on 24 September 2019, the Italian Constitutional Court legitimised assisted suicide under certain conditions: self-determination capacity, irreversible illness and intense physical/psychological suffering of the patient. This historic judgement surely paved the way for an evolution of the Italian legal framework on the matter but also raised some challenging medico-legal and bioethical questions. This study aims at analysing two of the most controversial among them: the inclusion of psychiatric patients among eligible patients for assisted suicide and the position of physicians related to their right to conscientious objection.
\end{abstract}

\section{Keywords}

Suicide, self-determination, capacity, irreversible illness, Italian Legalisation of Assisted Suicide, physician-assisted dying, psychiatry, suffering

\section{Background}

Issues about regulating physician-assisted dying in Italy have been put under the magnifying glass by the recent court case involving Marco Cappato. In 2017, he stood accused of incitement to suicide since he supported and helped Fabiano Antonini (known as DJ Fabo) access to assisted dying in Switzerland. Article 580 of the Italian Criminal Code punishes people "who incite another person or reinforce his/her intention to commit suicide or abet him/her in any manner to commit suicide". On 14 February 2018, the Milan Court of Assizes issued an order ${ }^{1}$ raising the question of the constitutional legitimacy of Article 580, namely was 580 applicable when the help had no bearing on the person's spontaneous and intentional decision to die? Order $207 / 2018^{2}$ issued on 16 November 2018 by the Italian Constitutional Court came in response to the question of constitutional legitimacy: it stated that prosecutions for assisted suicide cannot be declared unconstitutional, as a general rule. However, the Constitutional Court pointed out that there are situations where the principles of the Italian Constitution and the principle of human dignity may appear to be violated. The Court referred to the cases of patients "suffering from an incurable disease that causes them intolerable physical or psychological pain, being kept alive by life-sustaining treatments while capable of making free and conscious decisions". In such situations, the patients who want to cease being artificially kept alive can refuse their medical treatments but they cannot receive medical assistance in dying. According to the Constitutional Court, while it is illegal to help these patients to end their lives with dignity, it is inconsistent with the principles of self-determination and human dignity to allow them to interrupt medical treatments, an interruption that would prolong their inevitable dying process.

Against this background, the judges of the Court invited the Italian Parliament to fill the legal vacuum on the physician aid-in-dying issue and legislate on this subject by 24 September 2019, but it did not do so.

\footnotetext{
'Department of Anatomical, Histological, Forensic and Orthopaedic Sciences, Sapienza University of Rome, Rome, Italy

${ }^{2}$ Department of Medico-Surgical Sciences and Biotechnologies, Sapienza University of Rome, Rome, Italy
}

Corresponding author:

Andrea Cioffi, Viale Regina Elena, 336, 0016I Rome, Italy.

Email: an.cioffil9@gmail.com 
Hence, on 25 September 2019, the Constitutional Court confirmed its position and ruled that assisting a suicide is not a crime under certain conditions. Facilitating the suicidal intention of a patient shall not be punishable if his/her intention derives from an independent and free decision and if he/she is kept alive by life-support treatments, suffers from an irreversible condition causing intolerable physical or psychological pain and retains full mental capacity. All these conditions would be verified by the public health authorities after the approval of the local ethics committee. ${ }^{3}$ If all conditions are met, assisted suicide is now lawful in Italy.

We aim to draw attention to two specific bioethical and medico-legal issues that may emerge from this ruling: should psychiatric patients be entitled to obtain assisted suicide? What is the role of the physician and what problems could arise from the co-existence of assisted suicide and medical deontology?

\section{Perspectives for psychiatric patients}

Terminally ill cancer patients definitely satisfy the Constitutional Court's conditions ${ }^{4-7}$ but should psychiatric patients also be included here? The three main criteria for physician-assisted dying in Italy are the ability to make decisions for yourself (self-determination), irreversible pathology and intolerable physical or psychological suffering - and patients with severe psychiatric conditions could appear to comply with them.

\section{Capacity to decide freely and consciously}

Although psychiatric patients may suffer from serious illnesses, they are not always mentally incapable. Some have preserved decision-making capacity, particularly those who are receiving pharmacological and/or psychotherapeutic treatment. ${ }^{8}$ Indeed, they are legally entitled to sign bills of sale and contracts unless their legal status is altered by the court. Mentally capable psychiatric patients can understand the effects of a therapy and the risks of a pathology and consequently are able to sign informed consent for clinical treatment or to choose whether or not to end their own life. What is crucial is whether their desire to die is a free choice or the expression of their mental illness. If the latter, the disease must be treated with all available means by compulsory care if necessary to prevent them from committing suicide.

\section{Concept of irreversible pathology}

The definition of "irreversible" is "impossible to change or return to a previous condition". Today, many psychiatric conditions are considered irreversible. Certain diseases such as schizophrenia or severe cognitive decline cannot be successfully treated and cured. What can be treated are the symptoms and what can be improved is the patient's quality of life, not their disease. Treatment-resistant depression is also often considered as causing chronic and irreversible psychological suffering - it cannot be regarded as irreversible.

A disease that cannot be cured when all the available therapies used on the patients have been unsuccessful is irreversible. In the specific case of treatment-resistant depression, there would be potentially successful therapies in theory, but in practice there are impediments especially in Italy and especially concerning bioethical issues that restrict their use. For example, in clinical practice, the use of electroconvulsive therapy (ECT) or ketamine is quite limited, although it could help many cases. ${ }^{9-13}$ Psychiatric patients with treatment-resistant depression are among those who most frequently seek assisted suicide, ${ }^{14}$ but they must suffer from an irreversible pathology to see their request granted.

In other words, assisted suicide must be the last resort when all other options - including experimental therapies - have been tried; it must not be the easiest way to end a critical pathological condition which is difficult but not impossible to treat. Intense suffering such as the frequent desire to die in depressed patients requires intensive treatment - such as compulsory hospitalisation to prevent them from committing suicide. However, if they are defined as "irreversible" and would thus qualify for legally assisted suicide, it could establish a clinical trend leading to serious social, bioethical and medico-legal consequences.

\section{Psychological suffering which the patient perceives as intolerable}

"Intolerable" suffering as laid down by the Constitutional Court is generally subjective for the patient and what is intolerable varies from patient to patient.

Some argue that psychological suffering can be worse than physical pain ${ }^{15}$ because psychiatric patients' pain is intensified by their social conditions of isolation and stigmatisation. ${ }^{16,17}$ There are also cases of intense psychological suffering linked to serious physical conditions. For example, in cancer patients, the prior need is to treat their physical illness and evaluating psychological suffering perceived by the patient as intolerable would be secondary.

It is interesting to recall the European Court of Human Rights judgment in Haas v Switzerland (2007) in 2011: it is an understandable choice to assist a psychiatric patient to commit suicide, but we must distinguish between a wish to die as an autonomous and conscious decision or as the expression of a psychiatric disorder. ${ }^{18}$ 


\section{Perspectives for the role of the physician}

The doctors play a crucial role in the debate on the ethical implications of assisted suicide since it is the doctor who is central to the procedure. Doctors can put two entirely different interpretations on their role: (1) assisting suicide as an act of compassion and (2) ending suffering and helping their patient to die with dignity. On the other hand, treating death as an enemy on the basis that doctors swear (if they do still) the old Hippocratic Oath - to save lives and not kill. This would mean rejecting assisting a patient's death. This latter is the Italian National Medicine Board's position. In May 2019, it took an official position on medical aid-in-dying by asserting that death can never be an "ally" of a physician against a patient's suffering. ${ }^{19}$

The Constitutional Court's ruling also dealt with the doctor's role in assisted suicide. The judges of the Court stated that doctors who help a patient to die do not commit a crime if it is the patient's request. The Court, however, added that physicians are free to choose whether to grant the patient's request and are entitled to invoke conscientious objection to refuse to do it. After this ruling was issued, the National Medicine Board reconsidered its position on this matter and it now complies with the Court's ruling. The Board extended Article 17 of the Italian Code of Medical Deontology ("The physician must not administer or promote treatment intended to cause the death of the patient, even if requested by the patient him/ herself") by adding an exception. This addendum refers to the judgment 242/2019 of the Court when listing the necessary conditions to request assisted suicide - conscious and free choice of the patient kept alive by life-sustaining treatments, irreversible disease, intolerable physical or psychological suffering - and specifies that the doctor's choice to help must be assessed on a case-by-case basis. If all the aforementioned conditions favourably coexist, the medical practitioner shall not be subject to disciplinary action.

Is the Board's extension a fair compromise or a bad choice to make up for the lack of a real position on the matter? What is certain is that the debate on physicianassisted dying will continue along with discussions about legalisation of assisted suicide generally; if this were permitted it would have significant implications not just for patients, doctors and other health workers but also society as a whole.

\section{Conclusions}

It is essential to define in detail legal criteria and limits to physician-assisted dying. Italy, like other countries, requires a clear legislative framework covering access to assisted suicide that does not leave room for abuse or misinterpretation. The European Court of Human Rights ruling in 2013 (Gross v Switzerland) demonstrated the need for unambiguous legislation and convicted Swiss authorities because "Swiss law does not provide sufficient guidelines ensuring clarity as to the extent of" the right of obtaining a lethal dose on medical prescription. The lack of "State-approved guidelines defining the circumstances under which medical practitioners are authorised to issue the requested prescription" is likely to cause - the Court added - "a chilling effect on doctors" and a "considerable degree of anguish and uncertainty" on applicants. ${ }^{20}$

It is very important to evaluate the cases of psychiatric patients who decided their lives should end. The risk is to treat them as patients with fewer rights or cause a death that could have been avoided by different treatment. To minimise these risks, we must focus on what is most important: the recognition of masked psychopathological conditions, the assessment of the actual clinical severity, the analysis of nonresponse to treatment and the evaluation of how psychopathology itself influences the request for assisted suicide.

As regards the role of doctors, we need to consider whether the rules need to be extended to include other professionals, such as nurses who may become involved in the process. A physician's conscientious objection to assist dying may indeed excuse him from helping the patient to die but if other health workers were authorised to perform the procedure, the patient could see his/ her right to die guaranteed and the right to die must be there for all and safeguarded against discrimination.

\section{Acknowledgments}

We thank Chiara Avanzato for the editing of this manuscript.

\section{Declaration of conflicting interests}

The author(s) declared no potential conflicts of interest with respect to the research, authorship and/or publication of this article.

\section{Funding}

The author(s) received no financial support for the research, authorship and/or publication of this article.

\section{References}

1. Milan Court of Assizes. Order 1/18, 14 February 2018, www.gazzettaufficiale.it/eli/id/2018/03/14/18C00062/s1 (accessed 4 May 2020).

2. Italian Constitutional Court. Order 207/2018, 16 November 2018, www.cortecostituzionale.it/actionSch edaPronuncia.do $?$ anno $=2018 \&$ numero $=207 \quad$ (accessed 4 May 2020).

3. Italian Constitutional Court. Order 242/2019. 25 September 2019, www.cortecostituzionale.it/actionSch 
edaPronuncia.do ?anno $=2019 \&$ numero $=242$ (accessed 4 May 2020).

4. Oregon Public Health Division. Oregon death with dignity act annual reports, 1998-2015, https://public.health. oregon.gov/ProviderPartnerResources/Evaluation Research/DeathwithDignityAct/Pages/ar-index.aspx (1999-2016, accessed 3 October 2019).

5. Washington State Department of Health. Death with dignity act reports, 2009-2015, www.doh.wa.gov/Youand YourFamily/IllnessandDisease/DeathwithDignityAct (2010-2016, accessed 3 October 2019).

6. Onwuteaka-Philipsen BD, BrinkmanStoppelenburg A, Penning $\mathrm{C}$, et al. Trends in end-of-life practices before and after the enactment of the euthanasia law in the Netherlands from 1990 to 2010: a repeated crosssectional survey. Lancet 2012; 380: 908-915.

7. Dierickx S, Deliens L, Cohen J, et al. Comparison of the expression and granting of requests for euthanasia in Belgium in 2007 vs 2013. JAMA Intern Med 2015; 175: 1703-1706

8. Okai D, Owen G, McGuire H, et al. Mental capacity in psychiatric patients. Br J Psychiatry 2007; 191: 291-297.

9. Kellner $\mathrm{CH}$, Greenberg RM, Murrough JW, et al. ECT in treatment-resistant depression. AJP 2012; 169: 1238-1244.

10. Mathew SJ, Wilkinson ST, Altinay $M$, et al. Electroconvulsive therapy (ECT) vs. ketamine in patients with treatment-resistant depression: the ELEKT-D study protocol. Contemp Clin Trials 2019; 77: 19-26.

11. Trevithick L, McAllister-Williams RH, Blamire A, et al. Study protocol for the randomised controlled trial: ketamine augmentation of ECT to improve outcomes in depression (ketamine-ECT study). BMC Psychiatry 2015; 15: 257.

12. Carvalho AF, Berk M, Hyphantis TN, et al. The integrative management of treatment-resistant depression: a comprehensive review and perspectives. Psychother Psychosom 2014; 83: 70-88.

13. McIntyre RS, Filteau M-J, Martin L, et al. Treatmentresistant depression: definitions, review of the evidence, and algorithmic approach. J Affect Disord 2014; 156: 1-7.

14. Evenblij K, Pasman HRW, Pronk R, et al. Euthanasia and physician-assisted suicide in patients suffering from psychiatric disorders: a cross-sectional study exploring the experiences of Dutch psychiatrists. BMC Psychiatry 2019; 19 : 74.

15. Nicolini ME, Gastmans $\mathrm{C}$ and Kim SYH. Parity arguments for 'physician aid-in-dying' (PAD) for psychiatric disorders: their structure and limits. Am J Bioethics 2019; 19: 3-7.

16. Verhofstadt M, Thienpont L, Peters G-JY. When unbearable suffering incites psychiatric patients to request euthanasia: qualitative study. $\mathrm{Br} J$ Psychiatry 2017; 211: 238-245.

17. Bersani G, Rinaldi $R$ and Iannitelli A. The assisted suicide of Italians in Switzerland and the silence of psychiatry. Riv Psichiatr 2018; 53: 173-176.

18. European Court of Human Rights. Haas v. Switzerland (Application no. 31322/07), 20 January 2011, https://h udoc.echr.coe.int/eng\#\{\%22itemid \%22:[\%22001-102940 $\% 22]\}$ (accessed 3 November 2019).

19. Testo dell'audizione presso le Commissioni riunite Giustizia e Affari sociali della Camera dei Deputati. 30 maggio 2019, www.camera.it/application/xmanager/proj ects/leg18/attachments/upload_file_doc_acquisiti/pdfs/ 000/001/735/GIOVANNA_RAZZZANO_30.5.pdf (accessed 17 September 2019).

20. European Court of Human Rights. Gross v. Switzerland (Application no. 67810/10), 14 May 2013, https://hudoc. echr.coe.int/eng\#\{\%22itemid\%22:[\%22001-119703\% 22]\} (accessed 3 November 2019). 